\title{
Endophytic colonisation of tomato by the entomopathogenic fungus Beauveria bassiana: the use of different inoculation techniques and their effects on the tomato leafminer Tuta absoluta (Lepidoptera: Gelechiidae)
}

\author{
Natalia Allegrucci ${ }^{1 *}$, Maria Silvana Velazquez ${ }^{1}$, María Leticia Russo ${ }^{1}$, \\ Emilia Perez ${ }^{2}$, Ana Clara Scorsetti ${ }^{1}$ \\ ${ }^{1}$ Institute of Botany Carlos Spegazzini (FCNyM-UNLP), 53 \# 477, 1900 La Plata, Buenos Aires, Argentina \\ ${ }^{2}$ Center for Parasitological and Vector Studies (CEPAVE), CCT La Plata-CONICET-UNLP, Boulevard 120 S/N \\ between av. 61 y 62, La Plata (1900), Buenos Aires, Argentina
}

Vol. 57, No. 4: 331-337, 2017

DOI: 10.1515/jppr-2017-0045

Received: July 14, 2017

Accepted: November 17, 2017

*Corresponding address:

nataliaallegrucci@yahoo.com

\begin{abstract}
Fungal entomopathogens can naturally regulate populations of various insects. The entomopathogen Beauveria bassiana (Bals.- Criv.) Vuill. is also able to endophytically colonize different plants. Endophytic colonization by entomopathogens may provide a source of indirect interactions between fungi and insects and has been associated with the ability of the fungus to control insect pests. The tomato leaf miner, Tuta absoluta (Meyrick) is considered one of the most devastating pests of tomato (Solanum lycopersicum L.) and its difficult control is due to its miner habit, short life cycle, and high reproductive capacity. The aims of this study were: (i) to use three different techniques, i.e. leaf spraying, seed immersion and root dipping, for the endophytic inoculation of B. bassiana in tomato plants; and (ii) to assess the effect of $B$. bassiana on tomato leaf consumption and mortality of $T$. absoluta after inoculation. The percentage of colonization by B. bassiana was assessed 7, 14 and 28 days after inoculation. All inoculation techniques employed allowed the recovery of B. bassiana, although our results showed significant differences between techniques. Leaf spraying was the most effective, with the highest percentage of colonization recorded 7 days after inoculation. We also evaluated (i) the effect on the mortality of T. absoluta by direct contact with conidia of $B$. bassiana, and (ii) the effect on tomato leaf consumption and mortality by indirect contact through ingestion of inoculated plant tissues with B. bassiana. Mortality bioassays showed that B. bassiana infected T. absoluta, either by direct contact or indirectly, via ingestion of inoculated tomato leaves. Direct contact showed a higher percentage of mortality and a lower median survival time (MST) than indirect contact. Significant differences in the mortality percentages of T. absoluta after exposure with B. bassiana were found among the treatments and the control. Our results suggest that the endophytic inoculation of $B$. bassiana in tomato crops provides the basis for further investigation, which should focus on the virulence of the endophytic B. bassiana against T. absoluta.
\end{abstract}

Key words: Beauveria bassiana, biocontrol, endophytes, fungal entomopathogens, Solanum lycopersicum, Tuta absoluta

\section{Introduction}

Entomopathogenic fungi (EPF) are commonly found in diverse habitats and are known to infect many different taxa of arthropods. These fungi have also been found as rhizosphere colonizers in the surrounding environment of the host plant. In addition, recent evidence suggests that certain EPF species have the potential to engage in fungus-plant interactions, as fungal endophytes or plant disease antagonists, without causing any immediate negative effect or even promoting growth of host plants (Vega et al. 2008). 
However, although many entomopathogenic fungal endophytes might not be very abundant in most plant species, some taxa like Beauveria bassiana (Bals.-Criv.) Vuill. (Ascomycota: Hypocreales) have a wide range of plant hosts. The occurrence of EPF as natural endophytes also indicates that these fungi have complex life cycles, which can be completed in soil, invertebrates, and plants. Beauveria bassiana is an entomopathogenic fungus with worldwide distribution, which can live as a plant endophyte and usually does not cause visible damage to the host (Van Bael et al. 2005). It has been naturally isolated from several plant species, and artificially introduced into many others, such as tomato (Solanum lycopersicum L.) (Ownley et al. 2004), banana (Musa paradisiaca L.) (Akello et al. 2007), coffee (Coffea arabica L.) (Posada et al. 2007), sorghum (Sorghum bicolor Kuntze) (Reddy et al. 2009), pine (Pinus radiata D. Don) (Brownbridge et al. 2012), tobacco (Nicotiana tabacum L.), corn (Zea mays L.), wheat (Triticum aestivum L.) and soybeans (Glycine max L.) (Russo et al. 2015) by using various techniques. Colonization of plant tissues by $B$. bassiana has proved to provide protection against insect damage and inhibition of insect establishment and development (Ownley et al. 2004; Vega et al. 2008). In addition, protection against phytopathogens has been documented (Ownley et al. 2004). In Argentina, B. bassiana has been registered as entomopathogenic in Lepidoptera (Fresa 1979), Hemiptera (Toledo et al. 2008), Orthoptera (Pelizza et al. 2010), Diptera (Siri et al. 2005) and Coleoptera (López Lastra 1988).

The tomato leaf miner, Tuta absoluta (Meyrick) (Lepidoptera: Gelechiidae), was first described in Peru in 1917, and is now found throughout South America where it is considered to be one of the most devastating tomato pests (Barrientos et al. 1998). This pest was initially reported in eastern Spain in late 2006 and has subsequently spread throughout the Mediterranean Basin and Europe (Potting 2009). Since the time of its initial detection, it has caused serious damage to tomato crops in invaded areas and it is currently considered a major agricultural threat to European and North African tomato production (Abd El-Ghany et al. 2016). Although its main host is tomato, it also affects other Solanaceae, whether cultivated or not (Tropea Garzia et al. 2012). The control of T. absoluta is difficult due to its miner habit, short life cycle, and high reproductive capacity. The current management of $T$. absoluta is mainly based on the application of chemical insecticides. Nevertheless, a few active ingredients are effective against this pest without harming beneficial insects and pollinators at the same time. The use of synthetic insecticides, persistent or not, leads to resistant populations (Lietti et al. 2005) and to the disruption of natural biological control (Riquelme Virgala et al. 2006). Therefore, the use of integrative control methods (cultural, biological and biotechnological) becomes imperative, as the continued use of chemical insecticides could harm non-target organisms and the environment. The endophytic inoculation of tomato plants with $B$. bassiana could be a promising alternative for the biocontrol of T. absoluta.

\section{Materials and Methods}

\section{Fungal isolate}

The fungal strain used was B. bassiana LPSC 1067, obtained from the culture collection of "Instituto Spegazzini” (Universidad Nacional de La Plata), La Plata, Buenos Aires, Argentina. Selection of this fungal strain was based on its laboratory efficacy against other common pest insects in Argentina (Pelizza et al. 2012a, b). The species was identified using both molecular (GenBank accession number KF500409) and morphological data, as described by Russo et al. (2015).

\section{Conidial suspension}

Conidia were obtained from cultures grown on potato dextrose agar medium (PDA; Britania S.A., Buenos Aires, Argentina) after incubation for 10 days at $25^{\circ} \mathrm{C}$ in darkness. Conidia were harvested with disposable cell scrapers (Fisherbrand ${ }^{\circ}$ ) and placed in test tubes containing $0.01 \%(\mathrm{v} / \mathrm{v})$ Tween 80 (polyoxyethylene sorbitan monolaurate) (Merck ${ }^{\circ}$ ). Suspensions were vortexed for $2 \mathrm{~min}$, filtered through four layers of sterile muslin, and adjusted to $1 \times 10^{8}$ conidia $\cdot \mathrm{ml}^{-1}$ (Gurulingappa et al. 2010) after cell counting in a Neubauer haemocytometer. Conidial viability was assessed before every experiment (Goettel and Inglis 1997). This germination test was repeated for each stock suspension to maintain the constancy of the viability assessments. In all cases, the average viability of the conidia was over $95 \%$.

\section{Tomato plants}

Tomato seeds (Solanum lycopersicum cv. platense) were obtained from organic farms in the surroundings of La Plata city, Buenos Aires province, Argentina ( $\left.34^{\circ} 57^{\prime} 17^{\prime \prime} \mathrm{S}, 57^{\circ} 53^{\prime} 26^{\prime \prime} \mathrm{W}\right)$. None of these seeds had received prior chemical treatment. Seeds were planted in pots filled with approximately $86 \mathrm{~g}$ of an equally ground mixture of perlite, vermiculite, and soil (1:1:1), which was sterilized in an autoclave for 1 hour over three consecutive days prior to use. The seedlings were maintained in a greenhouse at $24^{\circ} \mathrm{C}$, with $70 \%$ relative humidity and under $12: 12 \mathrm{~h}(\mathrm{~L}: \mathrm{D})$ photoperiod by using $400 \mathrm{nmol} \cdot \mathrm{m}^{-2} \cdot \mathrm{s}^{-1}$ cold light lamps. 


\section{Inoculation techniques}

Tomato seeds were surface sterilized by placing them in $70 \%$ ethanol for $2 \mathrm{~min}$, then washed in sterile distilled water, followed by immersion in $0.5 \%$ sodium hypochlorite for $1 \mathrm{~min}$, and rinsed again in sterile distilled water (Brownbridge et al. 2012). Seeds were placed on sterile filter paper to dry for $30 \mathrm{~min}$ and then divided into two portions. One portion was used for seed inoculation and the other was used for leaf spraying and root dipping after seedling emergence. For seed inoculation, seeds (50 g) were immersed in $10 \mathrm{ml}$ of a conidial suspension $\left(1 \times 10^{8}\right.$ conidia $\left.\cdot \mathrm{ml}^{-1}\right)$ of B. bassiana for $24 \mathrm{~h}$, according to Brownbridge et al. (2012). Thereafter, seeds were dried on sterile tissue paper in a laminar flow cabinet for $30 \mathrm{~min}$, sown in pots at a depth of $4 \mathrm{~cm}$, and maintained in a greenhouse at $25^{\circ} \mathrm{C}$ under $12: 12 \mathrm{~h}$ (L : D) photoperiod. Control seeds were immersed in a conidia-free solution of $0.01 \%$ Tween ${ }^{\circledR} 80$.

In the case of leaf spraying and root dipping, seeds were planted in pots filled with approximately $86 \mathrm{~g}$ of an equally ground mixture of perlite, vermiculite, and soil $(1: 1: 1)$, which was sterilized in an autoclave for $1 \mathrm{~h}$ over three consecutive days prior to use. For the leaf spraying technique, leaves of $30 \mathrm{~cm}$ tall tomato plants (7 weeks old) were sprayed with $3 \mathrm{ml}$ of a conidial suspension $\left(1 \times 10^{8}\right.$ conidia $\left.\cdot \mathrm{ml}^{-1}\right)$ using a glass hand sprayer ( $30 \mathrm{ml}$ capacity). To avoid conidial runoff to the soil, the top of each pot was covered with aluminium foil (Posada et al. 2007). Control plants were sprayed with a conidia-free solution of $0.01 \%$ Tween ${ }^{\circledR} 80$.

For root dipping, we used seedlings three weeks after emergence. Each seedling was removed from the pot and rinsed three times with sterile distilled water. The ends of the roots were cut for better absorption and placed individually in test tubes with $2 \mathrm{ml}$ of a conidial suspension $\left(1 \times 10^{8}\right.$ conidia $\left.\cdot \mathrm{ml}^{-1}\right)$ after Akello et al. (2007). Each tube was covered with aluminium foil. The roots of control plants were submerged in sterile distilled water. Control plants were incubated at $25^{\circ} \mathrm{C}$, with $80 \%$ relative humidity and under $12: 12 \mathrm{~h}(\mathrm{~L}: \mathrm{D})$ photoperiod for $24 \mathrm{~h}$. Thereafter, both the control and treated plants were placed on sterile filter paper until completely dried and then replanted in the same pots. Seedlings in all treatments were watered as needed and maintained in a greenhouse at $24^{\circ} \mathrm{C}$, with $70 \%$ relative humidity and under $12: 12 \mathrm{~h}(\mathrm{~L}: \mathrm{D})$ photoperiod. For each of the inoculation techniques, 30 replicates were made for each treated seedling and 10 for the control.

\section{Evaluation of the presence of Beauveria bassiana as an endophyte}

Colonization of tomato seedlings by B. bassiana was assessed 7, 14 and 28 days after inoculation. To determine the potential presence of this fungus in the plant tissues, one leaf from each plant was randomly chosen and surface-disinfected by immersion in $0.5 \%$ sodium hypochlorite for $2 \mathrm{~min}$, followed by $2 \mathrm{~min}$ in $70 \%$ ethanol and rinsed with sterile distilled water (Arnold et al. 2001). Leaves were dried on sterile paper towels in a laminar flow cabinet and their edges were cut to remove dead tissue ensuing from the sterilization process. Complete disinfection of leaves was checked by plating $100 \mathrm{ml}$ of the last rinsing water of each sample onto PDA. In addition, subsamples of surface sterilized leaves were pressed against PDA to determine whether residual conidia retained the germinative potential (Gurulingappa et al. 2010). Leaves were cut into six sections of approximately $1 \mathrm{~cm}^{2}$ using a sterile scalpel. For each of the inoculation techniques tested, six leaf sections from each of the 30 treated plants and six leaf sections from the control plants were used.

A $0.1 \%$ stock of $0.02 \mathrm{~g}$ of each antibiotic (tetracycline, streptomycin, and penicillin) dissolved in $10 \mathrm{ml}$ sterile distilled water, followed by filter sterilization through a $0.2 \mu \mathrm{m}$ filter (Syringe filter sterile, E-Chrom Tech, Taiwan) was prepared and then $1 \mathrm{ml}$ of this stock was added to each litre of medium (Vega et al. 2008). Leaf sections were placed on dishes containing PDA with antibiotics. For each inoculation technique, we made 30 replicates for each treated seedling and 30 replicates for control plants. A total of 120 plants and 720 leaf sections were examined. The presence or absence of $B$. bassiana on the leaf sections was recorded after 10 days at $25^{\circ} \mathrm{C}$. Data were expressed as frequency of colonization (number of colonized leaf sections/total number of leaf sections $) \times 100$ (Petrini and Fisher 1986) .

\section{Insect rearing}

The colony of Tuta absoluta was established in 2011 from plant material infested with larvae collected from crops without any history of pesticides, in fields surrounding La Plata city, Argentina (3501'24.97”S, $\left.58^{\circ} 03^{\prime} 34.69^{\prime \prime} \mathrm{W}\right)$. The plant material was maintained under quarantine to discard the presence of potential diseases and parasites and then incorporated into the colony. Periodically, the colony was infused with wild stocks collected from the same geographical area, to maintain its genetic variability. Larvae were fed pesticide-free tomato seedlings (S. lycopersicum cv. platense) whereas adults were fed a $15 \%$ honey-water solution. The maintenance of the insect colony and all bioassays was carried out in the laboratory under controlled conditions: $25 \pm 2^{\circ} \mathrm{C}, 70 \pm 5 \%$ of relative humidity and $14: 10 \mathrm{~h}(\mathrm{~L}: \mathrm{D})$ photoperiod.

\section{Bioassay 1: Mortality of Tuta absoluta by direct contact with Beauveria bassiana}

To determine the infectivity of the selected strain against T. absoluta, 20 tomato leaf discs ( $2 \mathrm{~cm}$ diam.) 
were cut. Ten of them were immersed in a $0.001 \%$ solution of Tween ${ }^{\circledR} 80$ of $B$. bassiana $\left(1 \times 10^{8}\right.$ conidia $\left.\cdot \mathrm{ml}^{-1}\right)$ and the other 10 (controls) in a $0.001 \%$ conidia-free solution of Tween ${ }^{\circledR} 80$. The experiment consisted of four replicate test groups and four control groups, each group containing 10 2nd instar larvae. Leaf discs were placed in humid chambers with a second instar larva per disc. Every 24 h, larval mortality and larval instar were recorded. Experiments were repeated four times under comparable laboratory conditions. All bioassays were carried out in a growth chamber with controlled conditions $\left[25 \pm 2{ }^{\circ} \mathrm{C}, 70 \pm 5 \%\right.$ of relative humidity and $16: 8 \mathrm{~h}$ (L: D) photoperiod]. Larval mortality was evaluated daily for 10 days until the end of the experiment. Dead larvae were removed and immediately deposited in high-humidity chambers (sterile Petri dishes with filter paper dampened with sterile distilled water) and mycosis was confirmed under a stereoscopic microscope and by microscopical examination of the dead insects.

\section{Bioassay 2: Evaluation of leaf consumption and mortality of Tuta absoluta}

Tomato plants from seeds sown in a sterile organic substrate and maintained in a greenhouse $\left[24^{\circ} \mathrm{C}, 70 \%\right.$ relative humidity and $12: 12 \mathrm{~h}(\mathrm{~L}: \mathrm{D})$ photoperiod] were employed to evaluate the effect of $B$. bassiana as an endophyte on T. absoluta. Inoculation was performed by spraying the leaves with $30 \mathrm{ml}$ of a $0.001 \%(\mathrm{v} / \mathrm{v})$ conidial suspension in Tween ${ }^{\circledR} 80\left(1 \times 10^{8}\right.$ conidia $\left.\cdot \mathrm{ml}^{-1}\right)$ using a glass hand atomizer ( $35 \mathrm{ml}$ capacity). In the case of controls, leaves were sprayed with $30 \mathrm{ml}$ of a $0.001 \%(\mathrm{v} / \mathrm{v})$ conidia-free solution of Tween ${ }^{\circledR} 80$. Tomato treated leaves were inoculated four days before starting the test. Twenty tomato leaf discs ( $2 \mathrm{~cm}$ diam.) were cut. Ten of them corresponded to inoculated discs and 10 to control discs. The experiment consisted of four replicate test groups and four control groups, each group containing 10 2nd instar larvae. Leaf discs were placed in humid chambers with a second instar larva per disc. The discs were scanned 24, 48 and 72 hours post-treatment and the area consumed $\left(\mathrm{mm}^{2}\right)$ was calculated using the program ImageJ program. At 96 hours post-treatment, a foliolo or an untreated tomato leaf was added to each dish as food in order to continue the development of the different larvae. The larval mortality was evaluated daily under a stereomicroscope for 10 days and/or until the end of the experiment. Dead larvae were removed and immediately deposited in high-humidity chambers (sterile Petri dishes with filter paper dampened with sterile distilled water) and mycosis was confirmed under a stereoscopic microscope and by microscopical examination of the dead insects. To confirm the presence of B. bassiana in the internal tissues of each inoculated leaf disc, the remaining parts of the inoculated leaves used to cut the discs were individually disinfected (Arnold et al. 2001) as previously explained. Leaf pieces were dried on sterile paper towels in a laminar flow cabinet and the edges were cut to remove dead tissue resulting from the sterilization process. Thereafter, leaf pieces were placed on PDA in a Petri dish and incubated in the dark at $25^{\circ} \mathrm{C}$ for 10 days. In addition, subsamples of surface sterilised leaves were pressed against PDA to determine whether residual conidia retained the germinative potential (Gurunligappa et al. 2010).

\section{Data analysis}

Inoculation techniques: An analysis of variance (ANOVA) was used to evaluate the differences between inoculation techniques, the time of permanence of the fungus in the plant and the interaction between the two variables. The frequency of colonization (expressed as percentage) was angular transformed to stabilize the variance. ANOVA was performed with the software InfoStat 2007 (InfoStat 2001).

Bioassays 1 and 2: ANOVA and a posteriori Tuckey's test were performed to analyse the mortality data, using the program XLSTAT (Addinsoft XLSTAT for Excel, Paris, France, 2009). The leaf area consumed was calculated (in $\mathrm{mm}^{2}$ ) using the program ImageJ at 24, 48 and 72 hours post-treatment. Data were tested for normality using the Shapiro-Wilk test and analysis of data was performed either with Mann-Whitney's test or Student's t-test for two independent samples. The median survival time (MST) was calculated based on the Kaplan-Meier estimate of the survival distribution function (XLSTAT Life Software, 2014). Pairwise comparisons between survival curves were made by the log-rank test.

When the mortality in treated T. absoluta was $50 \%$ or higher, the MST was calculated based on the Kaplan-Meier Survival distribution function (XLSTAT Life Software, 2013). Pairwise comparisons between survival curves were made by the log-rank test.

\section{Results}

\section{Evaluation of Beauveria bassiana as an endophyte}

We evaluated the frequency of endophytic colonization of tomato plants by B. bassiana according to the inoculation technique (leaf spraying, root dipping, and seed immersion), post-inoculation time $(7,15$, and 28 days) and the interaction between these two variables. Results showed significant differences between inoculation techniques $(\mathrm{F}=13.9 ; \mathrm{df}=2 ; \mathrm{p}<0.001)$. Spraying yielded the highest frequency (10\%), 27 inoculated plants, followed by root dipping (5.56\%) and by seed immersion, which showed significantly lower 


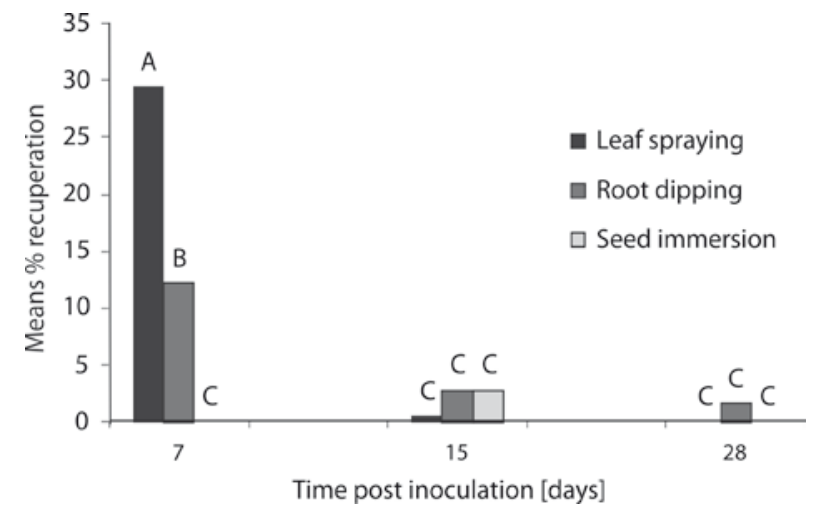

Fig. 1. Mean ( \pm standard deviation) colonization (\%) of tomato leaf sections 7, 15 and 28 days after inoculation with Beauveria bassiana, using different inoculation techniques (leaf spraying, root dipping and seed immersion). Bars with different letters indicate differences of statistical significance according to Tukey's test $(p<0.05)$

values (0.93\%), 16 and 2 inoculated plants respectively. Differences of statistical significance were found in the colonization of $B$. bassiana between post-inoculation times $(\mathrm{F}=36.06 ; \mathrm{df}=2 ; \mathrm{p}<0.001)$. The highest percentage of colonization was obtained 7 days after inoculation $(13.89 \%)$ and the lowest after 28 days $(0.56 \%)$. The interaction between inoculation techniques and post-inoculation times also showed significant differences $(\mathrm{F}=17.97 ; \mathrm{df}=4 ; \mathrm{p}<0.001)$. The highest values were recorded 7 days after inoculation using both leaf spraying (mean values: $29.44 \%$ ) and root dipping (mean values: $12.22 \%)$. The remaining values recorded for the interaction of these variables were significantly lower (Fig. 1). Likewise, it was observed that the endophytic implementation, which was estimated by the percent of post-inoculation recovery of B. bassiana, decreased over time. Beauveria bassiana was not isolated from the control plants or found in washings from surface sterilized leaves (Gurunligappa et al. 2010). In all cases, the average viability of the conidia was over $95 \%$.

\section{Bioassays 1}

Results from mortality bioassay showed that B. bassiana was able to infect $T$. absoluta by direct contact with conidia. Significant differences of mortality of T. absoluta were observed between treatment and control

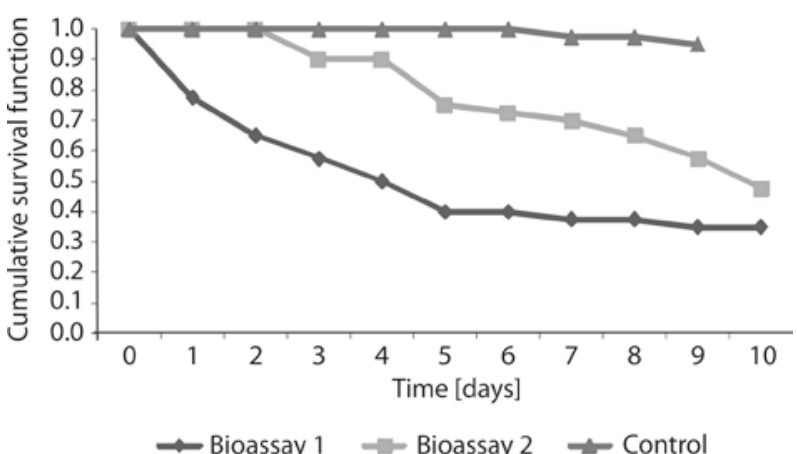

Fig. 2. Cumulative survival curves of Tuta absoluta in bioassay 1 , bioassay 2 and control

$(\mathrm{F}=215.09 ; \mathrm{df}=1 ; \mathrm{p}<0.0001)$. Infection by $B$. bassiana, in all dead larvae was confirmed undera stereoscopic microscope and by microscopical examination.

\section{Bioassays 2}

Colonization percentages for the plants utilized in the test were $86.6 \%$ and B. bassiana was not detected in any of the control plants. Significant differences of mortality of T. absoluta were observed between treatments and control $(\mathrm{F}=23.70 ; \mathrm{df}=1 ; \mathrm{p}=0.0028)$. Infection by $B$. bassiana, in all dead larvae was confirmed under a stereoscopic microscope and by microscopical examination. The leaf area consumed showed no significant differences between the bioassay and the control at 24 and 72 hours post-inoculation, however, significant differences between treatments were observed after $48 \mathrm{~h}$ (Table 1). Beauveria bassiana was not isolated from the control plants or found in washings from surface sterilized leaves (Gurunligappa et al. 2010).

Results from mortality bioassays showed that $B$. bassiana was able to infect $T$. absoluta, either by direct contact with conidia or indirectly by ingestion of tomato leaves colonized endophytically by B. bassiana (Fig. 2). The highest percentage of mortality was recorded in bioassay $1(87.5 \pm 5 \%)$, followed by bioassay $2(72.5 \pm 20.6 \%)$, while the controls presented $5 \pm 10 \%$ mortality. The MST recorded in bioassay $2(9.47 \pm 0.57$ days $)$ was higher than the results obtained in bioassay 1 (5.97 \pm 0.72 days), which shows a greater effectiveness of the conidia when they invade the host through the integument.

Table 1. Leaf consumed area by Tuta absoluta second instar larvae exposed to tomato leaf discs inoculated with Beauveria bassiana (bioassay 2) and to non-inoculated leaf discs (control)

\begin{tabular}{lccl}
\hline \multirow{2}{*}{ Treatments } & \multicolumn{3}{c}{ Area consumed $\left[\mathrm{mm}^{2}\right]$} \\
\cline { 2 - 4 } & $24 \mathrm{~h}^{*}$ & $48 \mathrm{~h}^{* *}$ & $72 \mathrm{~h}^{*}$ \\
\hline Control & $2.72( \pm 1.133) \mathrm{a}$ & $8.451( \pm 4,485) \mathrm{b}$ & $16.909( \pm 8.024) \mathrm{d}$ \\
Bioassay 2 & $2.553( \pm 1.061) \mathrm{a}$ & $11.987( \pm 6,300) \mathrm{c}$ & $20.3( \pm 9.712) \mathrm{d}$ \\
\hline
\end{tabular}

Mean values ( \pm standard deviation) of area consumed $\left(\mathrm{mm}^{2}\right)$ by second instar larvae of $T$. absoluta at 24,48 and 72 hours after the beginning of the test. Different letters indicate significant differences between treatments; ${ }^{*} \mathrm{t}$-Test for two independent samples; ${ }^{* *}$ Mann-Whitney's test 


\section{Discussion}

Fungal endophytes have evolved to inhabit both apoplastic and symplastic regions of plant tissues (Saikkonen et al. 1998), without causing visible harm or signs of disease in the host (Gimenez et al. 2007). Approximately 700 species from 90 genera of entomopathogenic fungi are known, including Acremonium, Beauveria, Cladosporium, Clonostachys and Isaria. Many of these genera are naturally found or proved fungal endophytes have evolved to inhabit both apoplastic and symplastic regions of plant tissues (Saikkonen et al. 1998), without causing visible harm or signs of disease in the host (Gimenez et al. 2007). Approximately 700 species from 90 genera of entomopathogenic fungi are known, including Acremonium, Beauveria, Cladosporium, Clonostachys and Isaria. Many of to be plant endophytes, but only 12 of them have been tested as biocontrol agents (Vega et al. 2008). In this work, we reported for the first time the ability of $B$. bassiana LPSC 1067 to colonize endophytically tomato plants. Other isolates of B. bassiana have been established previously as endophytes in various plants using different inoculation methods. Some examples are in potatoes by foliar spraying (Wagner and Lewis 2000), in tomatoes by stem injections (Bing and Lewis 1991) or coating seeds with $B$. bassiana conidial suspensions and in opium poppies after spraying leaves or coating seeds with B. bassiana conidial suspensions (Quesada-Moraga et al.2006). However, some studies indicated that leaves are poor routes of entry for this fungus in some plants, such as coffee (Posada et al. 2007). Our results indicate that $B$. bassiana was effectively established as an endophyte in tomato plants when inoculated either by leaf spraying, root dipping or seed immersion, and was reisolated from leaves 7, 14 and 28 days after its inoculation. The most effective inoculation technique was leaf spraying and the highest percentage of colonization was recorded 7 days after inoculation. It was noted that the endophytic colonization, estimated by the percentage of recovery of $B$. bassiana after inoculation, decreased over time. We demonstrated that the selected isolate of B. bassiana was able to colonize tomato plant tissues and was re-isolated from new leaves, which confirmed the establishment of the fungus in the plant tissues and its potential to move throughout them. This work showed that $B$. bassiana was able to infect $T$. absoluta by direct contact with conidia. Direct contact by leaf spraying showed a higher mortality rate and a lower MST value than indirect contact. Since T. absoluta is a leaf miner pest of tomato leaves, the endophytic colonization of tomato tissues by B. bassiana and its infective capacity of the pest $T$. absoluta provides the basis for further investigation, which should focus on the virulence of the endophytic B. bassiana against T. absoluta.

\section{Acknowledgements}

This research was partially supported by Fondo para la Investigación Científica y Tecnológica (FONCYT; PICT 2013-0543 and PICT 2014- 0677).

\section{References}

Abd El-Ghany N.M., Abdel-Razek A.S., Ebadah I.M.A., Mahmoud Y.A. 2016. Evaluation of some microbial agents, natural and chemical compounds for controlling tomato leaf miner, Tuta absoluta (Meyrick) (Lepidoptera: Gelechiidae). Journal of Plant Protection Research 56 (4): 372-379. DOI: https://doi.org/10.1515/jppr-2016-0055

Akello J., Dubois T., Gold C.S., Coyne D., Nakavuma J., Paparu P. 2007. Beauveria bassiana (Balsamo) Vuillemin as an endophyte in tissue culture banana (Musa spp.). Journal of Invertebrate Pathology 96 (1): 34-42. DOI: 10.1016/j. jip.2007.02.004

Arnold A.E., Maynard Z., Gilbert G.S. 2001. Fungal endophytes in dicotyledonous neotropical trees: patterns of abundance and diversity. Mycologycal Research 105 (12): 1502-1507. DOI: $10.1017 / 50953756201004956$

Barrientos Z.R., Apablaza H.J., Norero S.A., Estay P.P. 1998. Temperatura base y constante termica de desarrollo de la polilla del tomate, Tuta absoluta (Lepidoptera: Gelechiidae) [Base temperature and constant thermal development of the tomato moth, Tuta absoluta (Lepidoptera: Gelechiidae)]. Ciencia e Investigacion Agraria 25 (3): 133-137.

Bing L.A, Lewis L.C. 1991. Suppression of Ostrinia nubilalis (Hübner) (Lepidoptera: Pyralidae) by endophytic Beauveria bassiana (Balsamo) Vuillemin. Environmental Entomology 20 (4): 1207-1211.

Brownbridge M., Reay S.D., Nelson T.L., Glare T.R. 2012. Persistence of Beauveria bassiana (Ascomycota: Hypocreales) as an endophyte following inoculation of radiata pine seed and seedlings. Biological Control 61 (3): 194-200. DOI: 10.1016/j.biocontrol.2012.01.002

Gimenez C., Cabrera R., Reina M., Gonzales C.A. 2007. Fungal endophytes and their role in plant protection. Current Organic Chemistry Journal 11 (8): 707-720.

Goettel M.S., Inglis G.D. 1997. Fungi: Hyphomycetes. p. 213-248. In: "Manual of Techniques in Insect Pathology" (L.A. Lacey, ed.). Academic Press, San Diego, USA, 395 pp.

Gurulingappa P., Sword G.A., Murdoch G., Mc Gee P. 2010. Colonisation of crop plants by fungal entomopathogens and their effects on two insect pests when in plant. Biological Control 55 (1): 34-41. DOI: 10.1016/j.biocontrol.2010.06.011

InfoStat. 2001. User's Manual, Version 1. Córdoba: Universidad Nacional de Córdoba.

Lietti M.M.M., Botto E., Alzogaray R.A. 2005. Insecticide resistance in Argentine populations of Tuta absoluta (Meyrick) (Lepidoptera: Gelechiidae). Neotropical Entomology 34 (1): 113-119.

Lopez Lastra C.C. 1988. Nuevas especies de insectos hospedadores para el hongo Beauveria bassiana (Bals.) Vuill. (Deuteromycotina Hyphomycetes) en Argentina y consideraciones sobre su patogenia [New species of host insects for the fungus Beauveria bassiana (Bals.) Vuill. (Deuteromycotina Hyphomycetes) in Argentina and considerations about its pathogenesis]. Revista Facultad de Agronomía, UNLP 64 (1 y 2): 42-46.

Ownley B.H., Pereira R.M. Klingeman W.E., Quigley N.B., Leckie B.M. 2004. Beauveria bassiana a dual purpose biocontrol organism with activity against insect pest and plant pathogens. p. 255-269. In: "Emerging Concepts in Plant Health Management Research" (R.T. Lartey, A.J. Cesar, eds.), Signpost, City, India, 298 pp.

Pelizza S.A., Cabello M.N., Lange C.E. 2010. Nuevos registros de hongos entomopatógenos en acridios (Orthoptera: Acri- 
doidea) de la República Argentina [New records of entomopathogenic fungi in acridios (Orthoptera: Acridoidea) of the Argentine Republic]. Revista de la Sociedad Entomológica Argentina 69 (3-4): 287-291.

Pelizza S.A., Elíades L.A., Saparrat M.C.N., Cabello M.N. Scorsetti A.C., Lange C.E. 2012a. Screening of argentine native fungal strains for biocontrol of the grasshopper Tropidacris collaris: relationship between fungal pathogenicity and chitinolytic enzyme activity. World Journal of Microbiology and Biotechnology 28 (4): 1359-1366. DOI: 10.1007/ s11274.011.0935.8

Pelizza S.A., Eliades L.A., Scorsetti A.C., Cabello M.N., Lange C.E. 2012b. Entomopathogenic fungi from Argentina for the control of Schistocerca cancellata (Orthoptera: Acrididae) nymphs: fungal pathogenicity and enzyme activity. Biocontrol Science and Technology 22 (10): 1119-1129. DOI: $10.1080 / 09583157.2012 .713910$

Petrini O., Fisher P.J. 1986. Fungal endophytes in Salicornia perennis. Transactions of the British Mycological Society 87 (4): 647-651. DOI:10.1016/S0007-1536(86)80109-7

Posada F., Aime M.C., Peterson S.W., Rehner S.A., Vega F.E. 2007. Inoculation of coffee plants with the fungal entomopathogen Beauveria bassiana (Ascomycota: Hypocreales). Mycological Research 111 (6): 748-757. DOI: 10.1016/j.mycres.2007.03.006

Quesada-Moraga E., Landa B.B., Muñoz-Ledesma J., Jiménez-Díaz R.M., Santiago-Alvarez C. 2006. Endophytic colonization of opium poppy, Papaver somniferum, by an entomopathogenic Beauveria bassiana strain. Mycopathologia 161 (5): 323-329. DOI: $10.1007 / \mathrm{s} 11046.006 .0014 .0$

Reddy N.P., Ali Khan A.P., Devi U.K., Sharma H.C., Reineke A. 2009. Treatment of millet crop plant (Sorghum bicolor) with the entomopathogenic fungus (Beauveria bassiana) to combat infestation by the stem borer, Chilo partellus Swinhoe (Lepidoptera: Pyralidae). Journal of Asia-Pacific Entomology 12 (4): 221-226. DOI: 10.1016/j.aspen.2009.06.001

Riquelme Virgala M.B., Botto E.N., Lafalce C. 2006. Evaluación de algunos insecticidas para el control de la polilla del tomate, Tuta absoluta (Lepidoptera: Gelechiidae) y su efecto residual sobre el parasitoide Trichogrammatoidea bactrae (Hymenoptera: Trichogrammatidae) [Evaluation of some insecticides for the control of the tomato moth, Tuta $a b$ soluta (Lepidoptera: Gelechiidae) and its residual effect on the parasitoid Trichogrammatoidea bactrae (Hymenoptera: Trichogrammatidae)]. Revista de la Sociedad Entomológica Argentina 65 (3-4): 57-65.

Russo M.L., Pelizza S.A., Cabello M.N., Stenglein S.A., Scorsetti A.C. 2015. Endophytic colonisation of tobacco, corn, wheat and soybeans by the fungal entomopathogen Beauveria bassiana (Ascomycota, Hypocreales). Biocontrol Science and Technology 25: 475-480.

Saikkonen K., Faeth S.H., Helander M., Sullivan T.J. 1998. Fungal endophytes: a continuum of interactions with host plants. Annual Review of Ecology, Evolution, and Systematics 29: 319-343.

Siri A., Dikgolz V.E., Lopez Lastra C.C. 2005. Natural infections caused by the fungus Beauveria bassiana as a pathogen of Musca domestica in the neotropic. BioControl 50 (6): 937-940.

Tefera T., Vidal S. 2009. Effect of inoculation method and plant growth medium on endophytic colonization of sorghum by the entomopathogenic fungus Beauveria bassiana. Biocontrol 54 (5): 663-669. DOI: 10.1007/s10526.009.9216

Toledo A.V., Remes Lenicov A.M.M., López Lastra C.C. 2008. Host range findings on Beauveria bassiana and Metarhizium anisopliae (Ascomycota: Hypocreales) in Argentina. Boletín de la Sociedad Argentina de Botánica 43 (3-4): 211-220.

Tropea Garzia G., Siscaro G., Biondi A., Zappala L. 2012. Tuta absoluta, a South American pest of tomato now in the EPPO region: biology, distribution and damage. Bulletin OEPP/ EPPO Bulletin 42 (2): 205-210.

Van Bael S.A., Maynard Z., Rojas E., Mejia L.C., Kyllo D.A., Herre E.A. 2005. Emerging perspectives on the ecological roles of endophytic fungi in tropical plants. p. 181-191. In: "The Fungal Community its Organisation and Role in the Ecosystem" (J. Dighton, J.F. White, P. Oudemans, eds.). Taylor \& Francis, Abingdon, USA, $597 \mathrm{pp}$.

Vega F.E. 2008. Insect pathology and fungal endophytes. Journal of Invertebrate Pathology 98 (3): 277-279. DOI: 10.1016/j. jip.2008.01.008

Vega F.E., Posada F., Aime M.C. Pava-Ripoll M., Infante F., Rehner S.A. 2008. Entomopathogenic fungal endophytes. Biological Control 46 (1): 72-82.

Wagner B.L., Lewis L.C. 2000. Colonization of corn, Zea mays, by the entomopathogenic fungus Beauveria bassiana. Applied and Environmental Microbiology 66 (8): 3468-3473. 